

\title{
PENINGKATAN PEMBERDAYAAN SUMBER DAYA ALAM DAN SUMBER DAYA MANUSIA DI DESA BANYUASIH
}

\author{
Rubi Ginanjar $^{1}$, Syarifah Gustiawati ${ }^{2}$ \\ rubi.ginanjar@gmail.com ${ }^{1}$ \\ syarifah@fai.uika-bogor.ac.id ${ }^{2}$ \\ Dosen Fakultas Ilmu Kesehatan Universitas Ibn Khaldun ${ }^{1}$, Dosen Fakultas Agama Islam Ibn Khaldun ${ }^{2}$
}

\begin{abstract}
ABSTRAK
KKN Tematik Terintegrasi merupakan KKN yang orientasi programnya berfokus pada bidang tertentu sesuai dengan permasalahan kemasyarakatan dan arah kebijakan pembangunan sesuai yang ditentukan oleh pemerintah daerah tersebut. Tujuan dari KKN adalah meningkatkan efektifitas dan efisiensi program pembangunan melalui peningkatan kesadaran, kontribusi, eksistensi, dan kualitas hidup masyarakat dalam pelaksanaan program-program pembangunan. Adapun kegiatan KKN dimulai dengan tahap survei dan observasi ke tempat sasaran, pendekatan sasaran program, realisasi program dan berakhir dengan evaluasi kegiatan. Semua tahapan tersebut dilaksanakan dari tanggal 6 Agustus 2019 sampai dengan 6 September 2019 di Desa Banyu Asih Kecamatan Cigudeg Kabupaten Bogor. Program KKN Kelompok 47-48 ini melaksanakan program kerja dengan lebih menekankan kepada kualitas sumber daya. Kegiatan fisik kelompok 47-48 yaitu pembuatan penerangan jalan di kampung Cijambe Desa Banyu Asih. Dan kegiatan non fisik kelompok 47-48 antara lain Bimbel (bahasa inggris, matematika, bahasa arab, iqro), mengajar di instansi, seminar hukum, membuat Label merk untuk UMKM, database keuangan UMKM, membuat sample produk, gerakan menabung sejak dini, PHBS (perilaku hidup bersih dan sehat), bank sampah, Parenting Guru PAUD, lomba 17 Agustus, pentas seni dan acara perpisahan KKN.
\end{abstract}

\section{Kata Kunci : KKN, Banyu Asih, Program Kerja}

\section{PENDAHULUAN}

Berdasarkan Hasil Observasi serta analisis yang dilakukan oleh Kelompok 47 dan 48 KKN Universitas Ibn Khaldun di Desa Banyu Asih Kecamatan Cigudeg Kabupaten Bogor didapati permasalahan yang sangat rumit mulai dari permasalahan sampah yang tidak kunjung selesai, tingkat pendidikan yang rendah, kurangnya pengelolaan di bidang wirausaha dan infrastruktur yang tidak memadai. Namun, dalam rangka untuk mencapai suatu kemajuan, maka potensi-potensi yang ada di dalam diri seseorang haruslah dikembangkan. Bila dikembangkan secara teratur, terencana akan dapat membawa pada suatu tingkat sosial tertentu.

Dalam situs Wikipedia (2019) dipaparkan mengenai sumber daya alam (SDA) yaitu segala sesuatu yang berasal dari alam yang dapat digunakan untuk memenuhi kebutuhan hidup manusia, sedangkan sumber daya manusia (SDM) yaitu penduduk yang telah memasuki usia angkatan kerja baik yang belum bekerja maupun yang sudang bekerja. 
Kualitas sumber daya manusia (human resources) dari suatu negara merupakan salah satu faktor penting dan menentukan dalam usaha percepatan pembangunan. Sumber daya manusia (SDM) merupakan agen-agen pembangunan yang secara aktif dapat memberdayakan potensi sumber daya alam (SDA) menuju kearah yang lebih produktif.

Namun sebaliknya manusia juga dapat mengeksploitasi SDA tanpa melihat dampak negatif yang ditimbulkan. Oleh karena itu, pemerintah perlu menyadari pentingnya usaha pembangunan SDM melalui peningkatan pendidikan dan keterampilan bagi warganya (SDM) dan memanfaatkan potensinya secara efektip bagi pembangunan sosial-ekonomi dalam negara yang bersangkutan (M. Todaro, 2000).

Tujuan Program KKN ini adalah mengembangkan potensi sumber daya alam dan meningkatkan kualitas sumber daya manusia dalam berbagai bidang, diantaranya yaitu bidang pendidikan, agama, kesehatan, ekonomi, hukum dan bidang teknik.

\section{Geografis}

Desa Banyu Asih memiliki luas wilayah 929.569 Ha dengan luas perumahan atau pemukiman dan pekarangan $86 \mathrm{Ha}$, sawah $37 \mathrm{Ha}$, lading atau huma $34 \mathrm{Ha}$, tanah/bangunan pendidikan $1.230 \mathrm{Ha}$ dan tanah/bangunan peribadatan $1.311 \mathrm{Ha}$ serta memiliki 6 Rukun Warga (RW) dan 20 Rukun Tetangga (RT).

Desa Banyuasih memiliki batas wilayah administrative sebagai berikut :

\begin{tabular}{|c|l|l|}
\hline NO. & Arah & \multicolumn{1}{|c|}{ Berbatasan } \\
\hline 1. & Utara & $\begin{array}{l}\text { Desa Kampung } \\
\text { Sawah Kec. } \\
\end{array}$ \\
& & Rumpin \\
\hline
\end{tabular}

\begin{tabular}{|r|r|l|}
\hline 2. & Selatan & $\begin{array}{l}\text { Desa Banyu } \\
\text { Wangi Kec. } \\
\text { Cigudeg }\end{array}$ \\
\hline 3. & Barat & $\begin{array}{l}\text { Desa Tegal Lega } \\
\text { Kec. Cigudeg }\end{array}$ \\
\hline 4. & Timur & $\begin{array}{l}\text { Desa Rabak Kec. } \\
\text { Rumpin }\end{array}$ \\
\hline
\end{tabular}

\section{Tofografi Desa}

Desa Banyuasih merupakan desa yang dikelilingi oleh gunung dan perbukitan dengan ketinggian 342-371 mdp. Sebagian besar wilayah Desa Banyuasih adalah lerenggunung dengan kemiringan 20-30, dengan luas wilayah : $929.569 \mathrm{Ha}$.

\section{Hidrologi dan Klimatologi}

Aspek hidrologi suatu wilayah Desa sangat diperlukan dalam pengendalian dan pengaturan tata air wilayah desa. Berdasarkan hidrologinya, aliran-aliran sungai wilayah Desa Banyuasih membentuk pola Daerah aliran suangai. Yaitu : Tercatat beberapa sungai maupun selokan baik sekala kecil sedang dan besar.

Secara umum akhir-akhir ini terjadi Peningkatan kualitas curah hujan dan jumlah hujan dibandingkan keadaan selama tahun-tahun sebelumnya, hal ini dapat menjadi sangat berpengaruh terhadap Tanaman Holtikultura yang menjadi sumber kehidupan masyarakat petani buahbuahan.

\section{Demografi}

Jumlah Penduduk Desa Banyu Asih Sampai akhir bulan Januari Tahun 2019, tercatat sebanyak 6.762 Jiwa terdiri dari:

1. Laki laki sebanyak 3.707 Jiwa

2. Perempuan sebanyak 3.055 Jiwa

3. Jumlah KK sebanyak 1.498 Jiwa

Dengan kepadatan penduduk per / km2 1,34 Jiwa. 


\section{METODE}

\section{Metode Pendekatan}

Pendekatan yang digunakan dalam kegiatan ini dalam KKN ini yaitu dengan pendekatan sosial. Pendekatan sosial merupakan hal yang amat penting untuk dilakukan guna menunjang keberhasilan KKN. Oleh karena itu, penyelenggaraan KKN perlu didasari oleh pendekatan sosial yang tepat dan memadai, baik pada saat perencanaan, pelaksanaan, maupun pada tahap evaluasi.

Pendekatan sosial dilakukan melalui tahapan-tahapan yang sistematis, meliputi tahapan:

1. Pembukaan Hubungan

Dalam tahapan ini mahasiswa beserta dosen pembimbing dapat mengadakan diskusi atau lokakarya dengan semua pihak strategis di masyarakat tentang rencana kerja.

2. Pemeliharaan Hubungan

Hubungan yang telah terjalin melalui tahapan sebelumnya, selanjutnya perlu dipelihara dan dijaga agar suasana KKN tetap berjalan kondusif. Dalam pemeliharaan hubungan, komunikasi informal dapat memberikan hasil yang jauh lebih efektif.

\section{Pembinaan Hubungan}

Pembinaan hubungan terutama dilaksanakan oleh pengelola KKN (lembaga atau tim yang ditunjuk oleh perguruan tinggi yang bersangkutan) pada saat mengadakan pemantauan (monitoring) dan evaluasi terhadap rencana dan pelaksanaan kegiatan yang telah disetujui pihak-pihak strategis. Pada tahap ini dapat terjalin hubungan kerja sama antara Perguruan Tinggi dengan masyarakat yang tidak hanya sebatas KKN.

4. Mengakhiri Hubungan

Pada tahap ini peserta KKN berpamitan dengan masyarakat, baik secara formal maupun personal. Secara formal biasanya dilakukan secara seremonial dalam bentuk acara khusus pelepasan peserta KKN oleh masyarakat setempat.

\section{Partisipasi Masyarakat dalam Pelaksanaan Program}

Partisipasi masyarakat yang dapat dilakukan dalam kegiatan ini adalah sebagai berikut:

1. Menyediakan tempat tinggal bagi peserta KKN

2. Mempersiapkan tempat untuk pembinaan dan pelatihan.

3. Masyarakat bersama peserta $\mathrm{KKN}$ membangun infrastruktur

4. Pelaksanaan pengajian rutinan bersama peserta KKN

\section{Langkah Evaluasi}

Evaluasi program kerja dilakukan setiap program kerja berakhir atau telah dilaksanakan untuk mengetahui kekurangan dan kesalahan apa yang terjadi agar bisa dihindari pada pelaksanaan program kerja selanjutnya. Serta kelebihan dan keuntungan apa yang dimiliki untuk bisa dipertahankan sampai program kerja selanjutnya. Dan apakah sasaran serta tujuan dari setiap program kerja dapat tercapai sesuai harapan. 


\section{REALISASI PROGRAM}

Berikut adalah capaian program yang telah dilaksanakan:

\section{Bidang Ekonomi}


1. Gerakan gemar menabung sejak usia dini

Program Kerja Gerakan gemar menabung sejak usia dini dilaksanakan pada hari Rabu 11 Agustus 2019, sasaran pada program ini adalah seluruh anak-anak mulai dari tingkat PAUD dan MI atau SD dengan tujuan untuk mensosialisasikan kepada anak-anak kampumg cijambe tentang pentingnya menabung sejak usia dini dan menjelaskan manfaat yang di dapat dari menabung sejak usia dini sehingga hal tersebut dapat menjadi memotivasi anakanak untuk memulai kebiasaan untuk menabung.
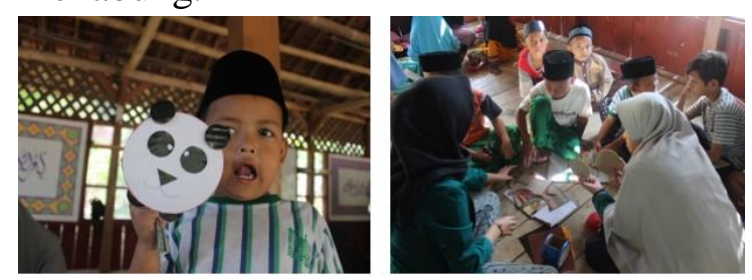

2. Menumbuhkan Kreativitas anak-anak yang bernilai ekonomis

Dilaksanakan Hari Rabu 21 Agustus 2019, sasaran pada program ini adalah seluruh anak-anak mulai dari tingkat PAUD dan MI atau SD dengan tujuan untuk memberikan pelatihan yang dapat menumbuhkan kreativitas anak-anak kampung cijambe dengan mengolah barang-barang bekas di sekitar yang sudah tidak terpakai namun dapat di olah sehingga bisa menjadi suatu hal yang bermanfaat dan memiliki nilai jual.
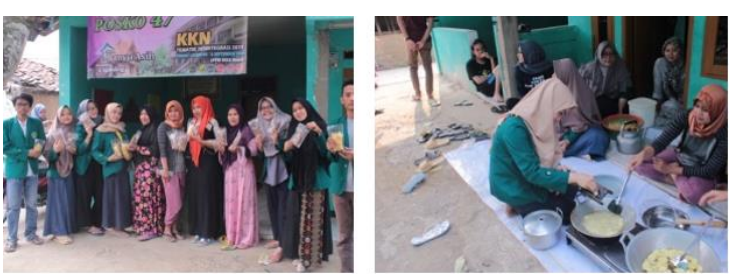

3. Pelatihan pembuatan produk keripik pisang berbagai rasa

Tepat pada hari Selasa 27 Agustus 2019 kelompok KKN 47 \& 48 melaksanakan Pelatihan pembuatan produk keripik pisang berbagai rasa yang diperuntukan Masyarakat Banyu Asih khususnya Ibu-Ibu PKK dengan tujuan memberikan pelatihan kepada masyarakat mengenai pengolahan hasil buah pisang salah satunya dengan pembuatan keripik pisang dengan berbagai rasa yang di kemas dengan pengemasan yang menarik. Sehingga di harapkan dengan proses pengolahan ini dapat meningkatkan harga dari hasil penjualan pisang tersebut, dan pelatihan ini di khususkan kepada ibu-ibu PkK karna di harapkan keripik pisang ini dapat menjadi salah satu usaha yang dimiliki oleh ibu-ibu PKK dan ibu-ibuk PKK ini yang sekaligus di harapkan dapat menjadi penggerak untuk terbukanya usaha baru di desa banyu asih dalam upaya pemanfaatan dari pada hasil pisang yang berlimpah di desa banyu asih ini.

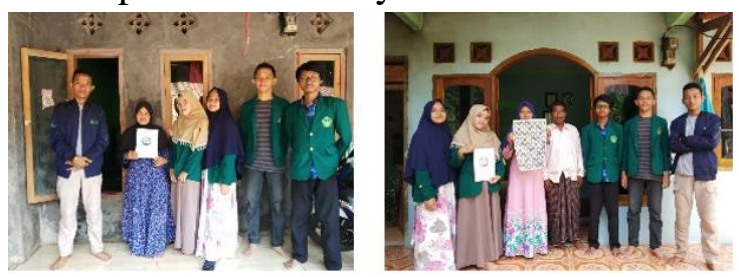

4. Pelatihan laporan pencatatan keuangan usaha dan pembuatan label usaha

Pelatihan ini dilakukan pada hari Minggu 1 september 2019 dengan sasarannya yaitu pemilik UMKM di Desa Banyu Asih yang tujuannya untuk memberi informasi produk agar produk yang di miliki UMKM ini memiliki ciri khas 
tersendiri dan produk tersebut dapat di kenal di pasaran. Pemberian pelatihan laporan pencatatan keuangan usaha ini bertujuan agar pelaku UMKM ini dapat mengetahui segala transaksi yang telah di lakukan mulai dari penjualan, pembelian, pendapatan dan pengeluaran yang telah di lakukan dan supaya pelaku UMKM tersebut dapat membedakan keuangan pribadinya dan keuangan usahanya.

\section{Bidang Hukum}


1. Seminar Membangun Kesadaran Hukum Terhadap Perlindungan Anak dan Pemberdayaan Perempuan

Seminar ini dilaksanakan pada tanggal 24 agustus 2019 pada jam 10.00 wib yang bertempat di aula kecamatan cigudeg. Kegiatan ini diselenggarakan oleh seluruh mahasiswa fakultas hukum yang sedang melaksanakan KKN dan di dukung oleh kelompok KKN dari berbagai desa di kecamatan cigudeg. Kegiatan ini bertema "Membangun kesadaran Hukum terhadap perlindungan anak dan pemberdayaan perempuan" yang di Narasumberi oleh Dr. Ibrahim fajri SH., ME.I beserta Team LBH UIKA dan bpk. Dudih syiaruddin selaku Ketua KPAI Bogor. Acara ini dihadiri oleh 69 peserta dari kalangan ibu-ibu PKK, tokoh masyarakat, polsek cigudeg, KNPI dan Mahasiswa yang sedang melaksanakan KKN di wilayah kecamatan cigudeg. Kegiatan ini bertujuan agar dapat Memberikan pemahaman Hukum kepada masyarakat agar kegiatan ini dapat memberikan pengetahuan dan masukan yang lebih mendalam bagi para kader dan masyarakat pada umumnya sehingga mampu meminimalisasi tindak KDRT di kecamatan cigudeg khususnya desa banyu asih, kekerasan dalam rumah tangga merupakan bentuk kekerasan berdasar asumsi bias gender tentang relasi laki-laki dan perempuan. KDRT bersumber pada cara pandang yang merendahkan martabat kemanusiaan dan pembakuan peran gender pada seseorang. Untuk itu, pencerahan atau pemahaman tentang KDRT itu dirasakan sangat perlu untuk menghindari KDRT yang sebagian besar banyak dialami kaum perempuan dan anak-anak. Serta memberikan pemahaman pada masyarakat betapa pentingnya sosialisasi UndangUndang perlindungan anak pasal $20 \mathrm{UU}$ No. 35 tahun 2014.

\section{Bidang Teknik}


1. Penerangan Jalan Umum Tenaga Surya (PJUTS)

Kurangnya Infrastuktur Desa seperti penerangan jalan membuat kelompok KKN 47-48 tergerak untuk membuat penerangan jalan bersama dengan warga bersama-sama mengerjakan PJUTS yang dipasang di 10 titik yang tersebar di wilayah Desa Banyu Asih, mulai dari pembuatan sampel PJUTS yang dilakukan pada tanggal 15 Agustus 2019 hingga pembuatan PJUTS yang dilakukan pada tanggal 20 Agustus 2019.

\section{Bidang Kesehatan}


1. Penyuluhan Kesehatan (PHBS)

Rendahnya

pengetahuan masyarakat mengenai kesehatan khususnya Perilaku Hidup Bersih dan Sehat yang 
membuat diadakannya program kerja penyuluhan kesehatan mengenai PHBS dengan sasaran Masyarakat Desa Banyu Asih khususnya Ibu-Ibu dan anak-anak guna meningkatkan derajat kesehatan bagi masyarakat, kegiatan ini dilakukan dua kali yakni pada tanggal 23 Agustus 2019 pukul 09.30 hingga pukul 11.00 WIB di Masjid Desa Banyu Asih Rt.01 Rw.01 yang dihadiri Ibu-Ibu dengan pembahasan PHBS ditatanan Rumah Tangga dan pada tanggal 29 Agustus 2019 penyuluhan dilakukan di MI Mathlaul Anwar pukul 10.00 Hingga pukul 12.00 WIB dengan pembahasan PHBS di tatanan Institusi Pendidikan (Sekolah).

2. Cek Kesehatan Gratis



Tujuan kegiatan ini untuk melihat kualitas kesehatan masyarakat Desa Banyu Asih dengan sasaran ibu-ibu, remaja dan bapak-bapak maupun lansia, cek kesehatan yang dilakukan berupa pengukuran berat badan, pengukuran tinggi badan dan tensi tekanan darah yang dilaksanakan pada hari Rabu 4 September 2019.

3. Penyuluhan Bank Sampah bersama Dinas Lingkungan Hidup Kabupaten Bogor

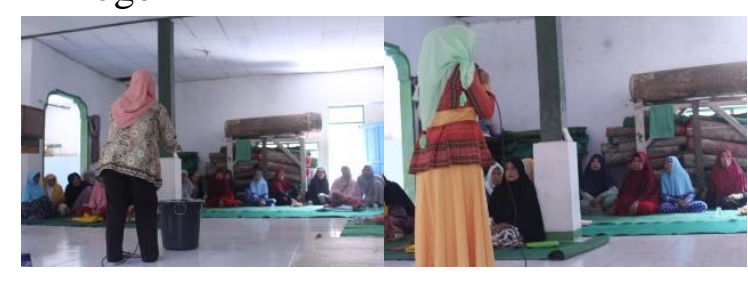

Permasalahan yang belum

terselesaikan hingga saat ini adalah permasalahan sampah, masyarakat Desa Banyu Asih hanya membakar sampah padahal pembakaran sampah hanya akan menambah polusi udara. Tepat hari jum'at
6 september 2019 pukul 09.00 hingga 12.00 WIB bersama Dinas Lingkungan Hidup Kabupaten Bogor melakukan Penyuluhan Bank Sampah yang dihadiri oleh Ibu-Ibu Desa Banyu Asih, diharapkan untuk kedepannya bank sampah ini akan menjadi solusi yang tepat bagi permasalahan sampah di Desa Banyu Asih.

\section{Bidang Pendidikan}

1. Bimbingan Belajar Bahasa Inggris

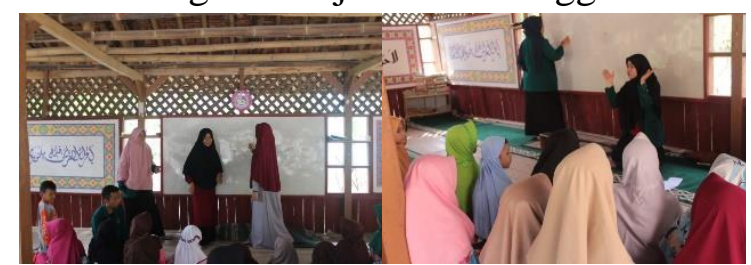

Belajar bukan hanya dilakukan di

Sekolah namun juga di luar sekolah seperti bimbingan belajar yang dilakukan setiap hari kamis pukul 13.30 sampai 15.00, bimbel ini mengajarkan Bahasa Inggris dan Bahasa Arab kepada anak-anak Desa Banyu Asih.

2. Pelatihan Guru PAUD dan Sharing Mengenai Sistem Pembelajaran dan Administrasi Sekolah

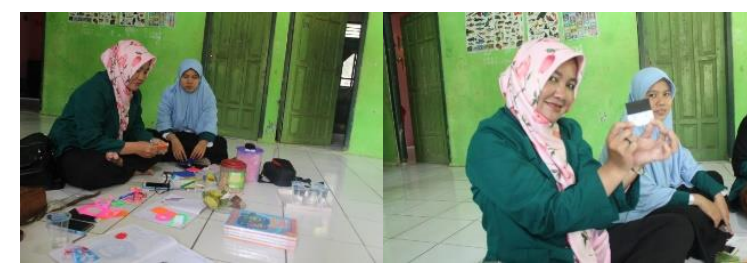

Tujuan dari pelatihan ini adalah untuk menumbuhkan kreativitas guru dalam mengajar agar proses pembelajaran dapat berjalan dengan baik dan dalam suasana yang menyenangkan serta penuh motivasi, materi pembelajaran pun akan mudah di pahami oleh siswa, serta dapat mempermudahkan proses pembelajaran bagi guru dan berbagi pendapat serta memberikam pelatihan dalam pembuatan perencanaan program pendidikan PAUD, dilaksanakan pada tanggal 16 Agustus 2019. 


\section{Parenting}

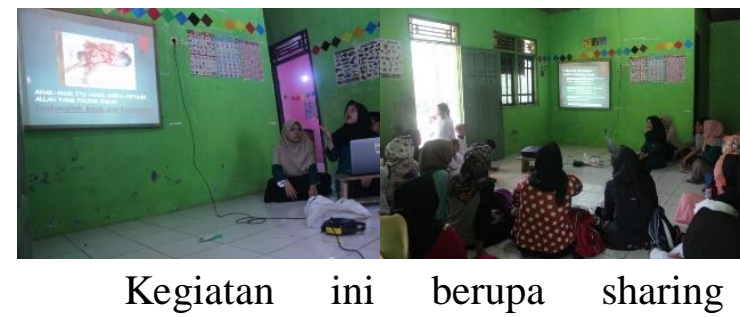

bersama ibu-ibu warga Desa Banyu Asih mengenai cara mendidik anak yang baik dan benar dilakukan tanggal 1 September 2019 dengan tema "Mendidik Anak Dengan Cinta dan Penuh Kasih Sayang" sasaran audiens adalah Ibu - Ibu Desa Banyu Asih.

\section{Lomba Cerdas Cermat dan Pidato}


Lomba yang diadakan khusus untuk anak-anak Desa Banyu Asih dengan tujuan untuk memberikan motivasi kepada anak anak untuk bisa mengembangkan minat dan prestasi dalam bidang pendidikan yang dilaksanakan pada tanggal 3 September 2019.

\section{Bidang Agama Islam}

1. Bimbel Iqro dan Al-Qur'an

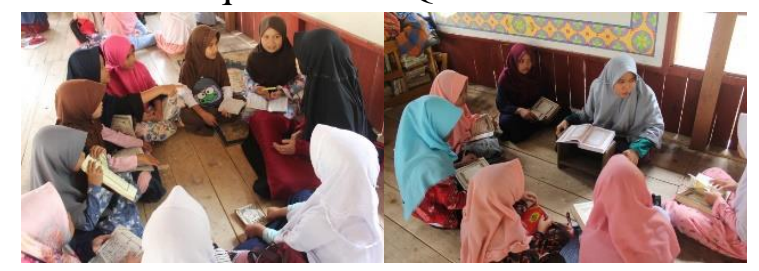

Tujuan dari kegiatan ini adalah untuk membantu anak-anak agar dapat membaca Al-Qur'an yang baik dan benar, dilakukan setiap hari senin pukul 13.30 sampai 15.00 dengan sasaran seluruh anak-anak Desa Banyu Asih.

2. Bimbel Do'a Sehari-hari dan Bahasa Arab



Kegiatan ini bertujuan agar minimal anak tahu kosa kata dalam Bahasa Arab, dan untuk mengajari do'a-do'a dalam kehidupan sehari-hari dan membiasakan anak-anak untuk berdo'a terlebih dahulu sebelum dan sesudah melakukan sesuatu pekerjaan yang dilaksanakan setiap hari jum'at.

\section{Pengajian Remaja (Ba'da Magrib)}

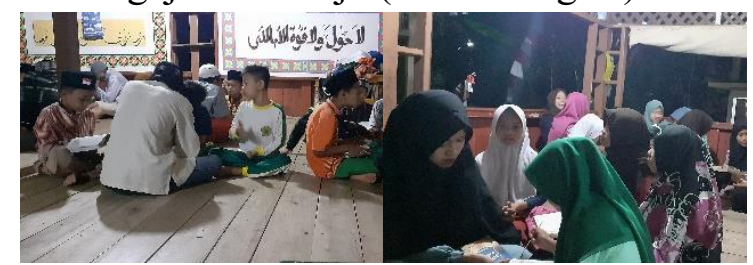

Kegiatan ini untuk membiasakan remaja Desa Banyu mengaji ba'da magrib, serta untuk mengisi waktu mereka dengan kegiatan-kegiatan yang positif yang dilakukan setiap hari selasa dan hari rabu.

4. Sharing Bersama Guru MI

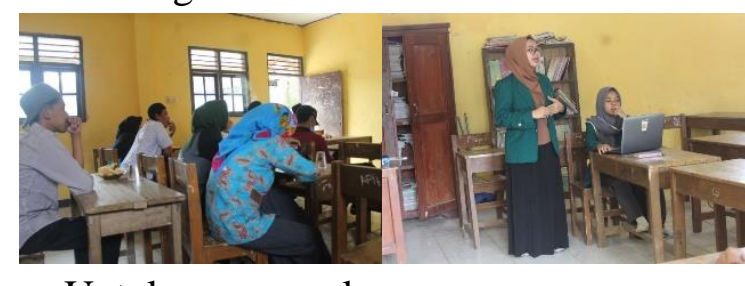

Untuk memperkaya wawasan guru terkait strategi, metode dan media pembelajaran bagi anak MI yang menarik dan menyenangkan sehingga dapat di praktekan dalam kegiatan belajar mengajar dilaksanakan pada tanggal 25 Agustus 2019.

5. Sharing Bersama Guru MTS

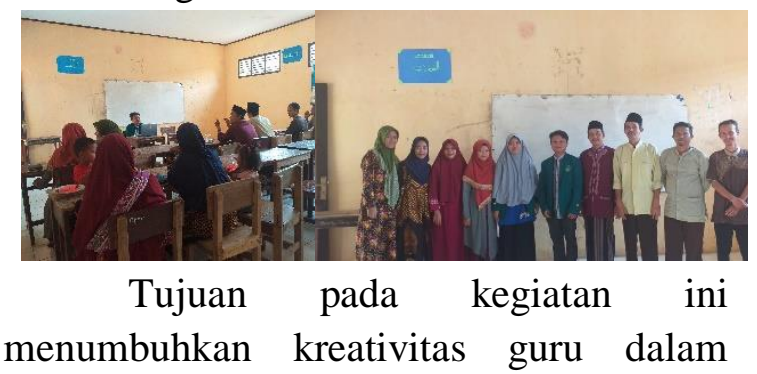


mengajar agar proses pembelajaran dapat berjalan dengan baik dan dalam suasana yang menyenangkan serta penuh motivasi, materi pembelajaran pun akan mudah di pahami oleh siswa, serta dapat mempermudahkan proses pembelajaran bagi guru, dilaksanakan pada tanggal 27 Agustus 2019.

6. Perlombaan Qory, Adzan dan Do'a Sehari-hari

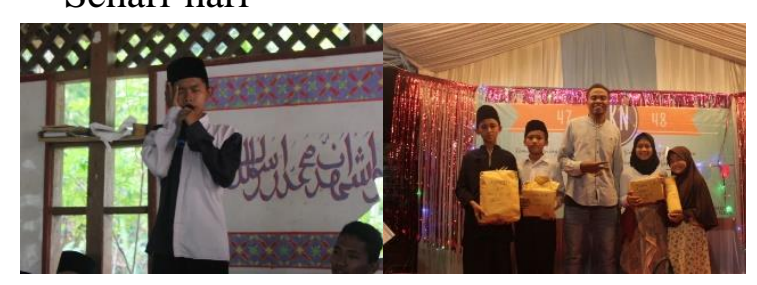

\section{KESIMPULAN}

Berikut beberapa kesimpulan yang dapat kami jabarkan selama program KKN yang berlangsung kurang lebih selama 30 hari di Desa Banyu Asih Kecamatan Cigudeg :

1. Terealisasinya program pengabdian kepada masyarakat yang dilakukan oleh mahasiswa dalam rangka mewujudkan program Universitas Ibn Khaldun Bogor sesuai dengan Visi dan Misi Universitas Ibn Khaldun Bogor.

2. Terbentuknya karakter building para

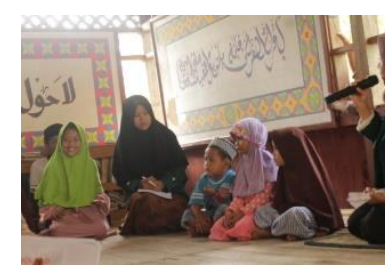

Perlombaan ini dilaksanakan tanggal 3 September 2019 di Balai Maul Barid dengan peserta anak-anak mulai dari Tingkat PAUD, MI hingga MTS. Tujuan dari perlombaan ini adalah untuk melatih mental anak-anak dan mengasah kemampuan serta menggali bakat dalam diri mereka.

mahasiswa dan mahasiswi yang mengikuti program KKN ini.

3. Terbentuknya program kerjasama langsung antara mahasiswa dan masyarakat yang bisa saling bersinergi dan saling menguntungkan.

4. Meningkatkan kepedulian dan rasa empati mahasiswa kepada permasalahan masyarakat, sehingga terjadinya perubahan perilaku mahasiswa. 


\section{DAFTAR PUSTAKA}

Kuliah Kerja Nyata. (online). https://id.wikipedia.org/wiki/Kuliah_ Kerja_Nyata. (diakses 21 Agustus 2019).

LPPM. 2018. Petunjuk Pelaksanaan KKN Tematik Terintergrasi 2018 Universitas Ibn Khaldun Bogor. Bogor : UIKA PRESS.

Profil Desa Banyu Asih Tahun 2019 Kecamatan Cigudeg Kabupaten Bogor. (Tidak Diterbitkan).

AzzisAbdul., DKK. 2016. Gemercik Air dari Banyuasih: Semangat Tak Terpadamkan. laporan hasil kegiatan kelompok KKN-PpMM UIN Syarif Hidayatullah Jakarta tahun 2016 di Desa Banyuasih, Kecamatan Cigudeg, Kabupaten Bogor.

Wakerkwa, Onius. 2016. Peranan Sumber Daya Manusia Dalam Meningkatkan Pembangunan Masyarakat Di Desa Umbanume Kecamatan Pirime Kabupaten Lanny Jaya. Jurnal Holistik, Tahun Ix No. 17a / Januari Juni 2016.
Prasetya, E. (2018). Pemberdayaan Masyarakat Tentang Kesehatan, Pendidikan dan Kreatifitas. Abdi Dosen: Jurnal Pengabdian Pada Masyarakat 2 (1), 19-25.

Sartika, Widya., Muhyani., Siti Rosada. 2018. Mengoptimalkan Potensi Sumber Daya Alam Dengan Meningkatkan Kualitas Sumber Daya Manusia Melalui Kepedulian Lingkungan Di Kampung Babakan Inpres Desa Cemplang. Bogor. Abdi Dosen Jurnal Pengabdian Pada Masyarakat Volume 03 Nomor 01, Maret 2019.

Soewartoyo dan Toni Soetopo. 2009. Potensi Sumber Daya Alam Dan Peningkatan Kualitas Sumber Daya Manusia Di Kawasan Massyarakat Pesisir. Kabupaten Bangka. Peneliti Pada Pusat Penelitian Kependudukan Lembaga Ilmu Pengetahuan Indonesia (PPK-LIPI) Vol. IV, No. 2, 2009.

Kementrian Kesehatan RI. 2011. Pedoman Pembinaan Perilaku Hidup Bersih dan Sehat (PHBS). Jakarta: Kementrian Kesehatan RI. 